\title{
Relação entre vínculo de apego e desenvolvimento cognitivo, linguístico e motor
}

\author{
Bárbara Saur ${ }^{1}$ \\ Isac Bruck ${ }^{1}$ \\ Sérgio Antonio Antoniuk ${ }^{1}$ \\ Tatiana Izabele Jaworski de Sá Riechi ${ }^{1}$ \\ ${ }^{1}$ Universidade Federal do Paraná, PR, Brasil
}

\begin{abstract}
Resumo
O estabelecimento de uma relação de apego segura é importante, pois fornece à criança segurança para que ela possa explorar o ambiente, atividade essencial para o desenvolvimento infantil. Este estudo tem como objetivo investigar se crianças com padrão de apego seguro e inseguro diferem quanto ao desempenho cognitivo, linguístico e motor. Participaram do estudo 50 crianças, com idades entre 12 e 25 meses. Foram utilizados um questionário de anamnese, a Situação Estranha de Ainsworth, as Escalas Bayley de Desenvolvimento Infantil - 3 3 ed. e o questionário Estilo Materno como instrumentos de avaliação. Os resultados apontam diferença entre os grupos no desempenho cognitivo e de linguagem. Crianças com padrões inseguros de apego obtiveram menores escores nos testes que avaliam o desenvolvimento dos dois domínios. Estes resultados demonstram a importância da relação entre mãe e filho como um fator de proteção do desenvolvimento.
\end{abstract}

Palavras-chave: Relação mãe-filho; Desenvolvimento infantil; Cognição.

\section{Relationship between attachment bond and cognitive, language and motor development}

\begin{abstract}
Establishing a secure attachment relationship is important because it provides security for the child to explore the environment, an essential activity for child development. This study aims to investigate whether children with a secure and insecure attachment pattern differ in cognitive, linguistic and motor performance. Fifty children, aged between 12 and 25 months, participated in the study. An anamnesis questionnaire, the Ainsworth Strange Situation, the Bayley Child Development Scales $-3^{\text {rd }}$ ed. and the Maternal Style questionnaire were used as assessment tools. The results show a difference between groups in cognitive and language performance. Children with insecure attachment patterns had lower scores on tests that assessed the development of both domains. These results demonstrate the importance of the relationship between mother and child as a protective factor of development.
\end{abstract}

Keywords: Mother-child relations; Childhood development; Cognition.

\section{Relación entre el vinculo de apego y el desarrollo cognitivo, lingüístico y motor}

Resumen

El establecimiento de una relación de apego seguro es importante porque proporciona seguridad al niño para que pueda explorar el ambiente, actividad esencial para el desarrollo infantil. En este estudio, se tiene como objetivo investigar si los niños con patrón de apego seguro e inseguro difieren en cuanto al desempeño cognitivo, lingüístico y motor. El estudio incluyó a 50 niños con edades comprendidas entre 12 y 25 meses. Se utilizó una ficha de anamnesis, la situación extraña de Ainsworth, las Escalas Bayley de Desarrollo Infantil - 3ㅜ ed. y el cuestionario Estilo Materno como instrumentos de evaluación. Los resultados apuntam a una diferencia entre los grupos en el desempeño cognitivo y del lenguaje. Los niños con tipos de apego inseguro tenían puntuaciones más bajas en las pruebas que evalúan el desarrollo de los dos campos. Estos resultados demuestran la importancia de la relación entre la madre y el niño como un factor de protección del desarrollo.

Palabras clave: Relaciones madre-hijo; Desarrollo infantil; Cognición. 


\section{Introdução}

A relação entre mãe e filho(a) constitui um fator importante para o desenvolvimento infantil. O tipo e a qualidade da interação durante os primeiros anos de vida ajudam a modelar o desenvolvimento e o funcionamento cerebral da criança, contribuindo positiva ou negativamente no desenvolvimento global da criança e do seu comportamento (Sajaniemi et al., 2001; Sullivan, Perry, Sloan, Kleinhaus, \& Burtchen, 2011).

A qualidade da interação entre a criança e o seu cuidador reflete na relação de apego que é estabelecida entre a díade. A teoria de apego foi elaborada originalmente por John Bowlby, na qual o autor descreve a relação estabelecida entre o bebê e o seu cuidador. Através do relacionamento com seu cuidador principal, a criança desenvolve um dos quatro padrões de apego: seguro, inseguro evitativo, inseguro ambivalente ou desorganizado. Enquanto os três últimos refletem uma relação disfuncional com o cuidador, o padrão de apego seguro é um fator de proteção ao desenvolvimento (Bowlby, 2002; Main, 1983)

Várias características, da mãe, da criança e do contexto, exercem influência no desenvolvimento do padrão de apego. Relacionadas ao cuidado maternal, as características do estilo materno exercem influência no relacionamento entre mãe e filho. A responsividade e sensibilidade maternas (Bowlby, 2002), o suporte emocional e o estilo educativo estão relacionados ao desenvolvimento da relação de apego segura na criança (Simões, Farate, Soares, \& Duarte, 2013). As condições de nascimento, prematuridade e nível de desenvolvimento cognitivo da criança também são importantes fatores, assim como características do contexto familiar e social, como o nível de desenvolvimento socioeconômico, presença de estressores familiares, suporte social e tipo de família (Cassidy \& Shaver, 2008).

A qualidade da relação de apego estabelecida no primeiro ano de vida influenciará fortemente o desenvolvimento posterior da criança, tanto nos aspectos emocionais, como cognitivos. Uma vez estabelecida uma relação de apego segura, será possível para a criança usar a mãe como uma base segura a partir da qual ela se sentirá confiante para explorar o ambiente a sua volta e aumentar a qualidade da exploração e da brincadeira (Cassidy \& Shaver, 2008). Assim, a relação de apego segura desempenha um papel importante na organização do comportamento da criança e promove a exploração mais competente (Pallini, Baiocco, Baumgartner, Belluci, \& Laghi,
2016), o que possibilita à criança obter informações do ambiente e dos objetos que ali estão, servindo, então, como uma janela para o seu desenvolvimento cognitivo ao mesmo tempo em que promove o desenvolvimento motor (Jouen \& Molina, 2005).

A competência exploratória sofre influência do padrão de apego e, ao mesmo tempo, influencia o desenvolvimento cognitivo, motor e linguístico. $\mathrm{O}$ desenvolvimento destas competências pode ser afetado, então, pelo tipo de relação de apego formada. $\mathrm{O}$ apego seguro proporciona uma melhor possibilidade para o desenvolvimento, enquanto que o apego inseguro poderá ocasionar um nível mais baixo (Ding, $\mathrm{Xu}$, Wang, Li, \& Wang, 2014).

Isso decorre em razão de que o funcionamento cerebral recebe forte influência das experiências iniciais, as quais podem alterar o número de neurônios no cérebro, selecionando aqueles que irão sobreviver, bem como aumentar ou diminuir a complexidade de suas ramificações axonais e dendríticas e alterar o número de sinapses (Sullivan, 2012). A arquitetura celular do córtex cerebral é esculpida pelas experiências no ambiente social proporcionado pela relação de apego, e mudanças substanciais no cérebro em desenvolvimento são induzidas através desta relação (Gander \& Buchheim, 2015).

Contudo, para que a criança consiga exibir os comportamentos de apego e estabelecer essa relação, determinados componentes cognitivos precisam estar presentes. Aprender sobre seu cuidador é essencial para a formação de um vínculo de apego seguro (Bowlby, 2002). É necessário que a criança já tenha desenvolvido algumas funções mentais, como permanência de objeto; memória; e representações mentais da figura de apego, de si própria e do ambiente, a fim de que consiga discriminar sua figura principal de apego das demais figuras do seu cotidiano e saiba que a mesma existe ainda que não esteja em seu campo de visão. Ao mesmo tempo, capacidades motores de buscar a figura de apego e explorar o ambiente também são necessárias. Como é influenciado por fatores biológicos, o nível de maturidade cognitiva no qual a criança se encontra pode exercer influência no padrão de apego que ela irá estabelecer (Cassidy \& Shaver, 2008).

A influência exercida pela relação de apego durante os primeiros anos de vida no desenvolvimento emocional e social da criança, bem como nos seus futuros relacionamentos, já está estabelecida. Contudo, os resultados não são conclusivos no que diz respeito à influência do padrão de apego no desenvolvimento cognitivo, linguístico e motor. No Brasil, apesar da importância do tema e do impacto que o conhecimento proveniente de tais estudos podem gerar no trabalho 
realizado com a primeira infância, nenhuma pesquisa com esta temática e dentro da idade proposta foi encontrada.

Assim, o presente estudo tem como objetivo investigar se crianças, com idades entre 12 e 25 meses, com padrão de apego seguro e inseguro diferem quanto ao desempenho cognitivo, linguístico e motor.

\section{MÉTODO}

\section{Participantes}

A amostra de conveniência foi composta por 50 crianças, de ambos os sexos, com idade entre 12 e 25 meses. Os critérios de inclusão abarcaram a idade entre 12 e 25 meses para as crianças, assentimento de um dos pais em participar da Situação Estranha de Ainsworth e o consentimento dos pais através da assinatura do Termo de Consentimento Livre e Esclarecido (TCLE). Crianças com malformações congênitas, síndromes genéticas ou comprometimento sensorial grave, com idade menor que 12 meses e maior que 25 meses, com pais que não aceitaram participar da Situação Estranha de Aisnworth e que não assinaram o TCLE foram excluídas.

Todas as crianças eram atendidas por uma das três instituições participantes da pesquisa, a saber, um centro de especialidade de um hospital, um centro de educação infantil e um centro de atendimento psicológico de uma universidade. As instituições foram escolhidas de forma intencional, devido à disponibilidade das mesmas em participar da pesquisa.

\section{Instrumentos}

Foram utilizados 4 instrumentos de avaliação. O Questionário sociodemográfico, desenvolvido pelos autores, teve por objetivo traçar o perfil da população de estudo. É constituído por itens referentes à condição socioeconômica da família, estrutura familiar e dados neonatais, e aplicado a um dos pais. A elaboração dos itens referentes às características socioeconômicas seguiram as diretrizes do Critério de Classificação Econômica Brasil 2015 (ABEP, 2014).

A Situação Estranha de Ainsworth, desenvolvida por Ainsworth e colaboradores (1978), foi utilizada para avaliar o padrão de apego da criança. Trata-se de um processo experimental, que sujeita a criança a diferentes situações, por meio das quais os avaliadores analisam o comportamento da criança quando esta se encontra sozinha, na companhia da figura de apego e com uma pessoa estranha. Neste estudo, como figuras de apego, a participação do pai ou da mãe foi requisitada. A escolha destes como figura de apego ocorreu uma vez que são eles, frequentemente, os cuidadores principais da criança e, portanto, suas figuras de apego.

As Escalas Bayley do Desenvolvimento Infantil III (BSID III) (Bayley, 2006) foi utilizada para avaliar o desenvolvimento. O teste é composto por cinco escalas independentes que avaliam cinco domínios do desenvolvimento: cognição; linguagem, composta por subescalas de linguagem receptiva e linguagem expressiva; motricidade, composta por subescalas de motricidade fina e motricidade grossa; social-emocional e comportamental-adaptativo. No presente estudo foram utilizadas as escalas cognição, de linguagem e de motricidade, aplicadas diretamente na criança, e o Questionário Social-emocional, de frequência de comportamento da criança, feito com os pais.

Apesar de a BSID III não ter sido validada para a população brasileira, o manual e o caderno de aplicação foram traduzidos e maior atenção foi dada durante a aplicação quanto às questões culturais. As tabelas utilizadas para a classificação dos resultados foram as do estudo de padronização americano.

A Escala de Estilo Materno e Paterno (Seidl de Moura \& Ribas Jr., 2003) é um conjunto de quatro escalas, aplicadas individualmente à mãe, cada uma com 17 itens: maternagem real e ideal e paternagem real e ideal. Cada uma das quatro escalas contém itens de três subescalas: Didática, Social e Disciplina. Foi desenvolvido por M. Bornstein e colaboradores no contexto de um programa de pesquisa transcultural e longitudinal (Bornstein et al., 1996). O instrumento foi traduzido e adaptado por Maria Lucia Seidl de Moura e Rodolfo de Castro Ribas Jr. (2003), e teve sua consistência avaliada. No presente estudo o instrumento foi aplicado somente às mães e utilizada somente a escala de maternagem real, uma vez que somente as mães participaram da pesquisa.

\section{Procedimentos}

Foi realizado contato com um ou ambos os pais da criança, nas próprias instituições participantes da pesquisa ou por telefone, quando foi explicado a respeito do estudo e feito o convite para participação na pesquisa. Se aceito o convite, era marcado um horário para a realização das avaliações. No dia da avaliação, era requisitada aos pais a assinatura do TCLE e posteriormente se procedia às avaliações, que duraram cerca de 90 minutos.

\section{Análise dos dados}

Os dados obtidos no Questionário sociodemográfico foram analisados e descritos por médias e desviopadrão para variáveis quantitativas e percentual e frequência para as variáveis qualitativas. A Situação 
Estranha de Ainsworth foi gravada em vídeo. A análise foi feita conjuntamente por dois avaliadores que já tinham conhecimento anterior do instrumento. Os comportamentos da criança em toda a situação estranha foram categorizados com relação a variáveis interacionais discretas. Com base nas categorizações foi realizada uma análise qualitativa e a criança foi classificada em um dos tipos de relação de apego: apego seguro (B), apego inseguro evitativo (A), apego inseguro ambivalente (C) ou apego desorganizado (D). Os escores brutos da BSID III (Bayley 2006) foram convertidos em escores escalares, a partir dos quais fezse a análise por média e desvio-padrão. Para a análise dos dados do Questionário Social-emocional da BSID III (Bayley 2006) foram consideradas as respostas a cada item, descritas por frequência de resposta, assim como o escore escalar total. Para a análise dos resultados da Escala de Estilo Materno e Paterno foram consideradas as respostas a cada item individualmente.

Os resultados obtidos foram descritos por médias, medianas, valores mínimos, valores máximos e desvios padrões. Para variáveis qualitativas foram apresentados frequências e percentuais. Para a comparação de grupos definidos de acordo com a classificação da relação de apego com variáveis quantitativas foi considerado o teste $t$ de Student para amostras independentes ou o teste não paramétrico de Mann-Whitney, quando apropriado. Em relação a variáveis qualitativas, as comparações foram feitas utilizando o teste exato de Fisher ou o teste de Qui-quadrado. Os dados foram analisados com o programa computacional Statistical Package for the Social Sciences - IBM SPSS Statistics, versão 20.0 .

\section{Considerações éticas}

O projeto da pesquisa foi avaliado pelo Comitê de Ética em Pesquisa com Seres Humanos do Hospital das Clínicas da Universidade Federal do Paraná, e obteve parecer favorável, sob CAAE 36364814.4.0000.0096.

\section{Resultados}

A amostra foi composta por crianças de ambos os sexos $(n=50)$. Na análise do padrão de apego foram consideradas as quatro classificações: A (inseguro evitativo), B (seguro), C (inseguro ambivalente) e D (desorganizado). O padrão de apego seguro (B) foi a classificação preponderante na amostra, sendo encontrado em 41 (82\%) das crianças da amostra. As demais classificações apareceram em igual proporção, $3(6 \%)$ para cada tipo de apego, a saber inseguro evitativo (A), inseguro ambivalente (C) e desorganizado (D).
Devido à baixa amplitude da amostra, os padrões inseguros de apego (A, C, e D) foram agrupados e formaram uma categoria, resultando em 9 (18\%) crianças com apego inseguro e 41 (82\%) com apego seguro. Das 41 crianças com apego seguro 16 (39\%) eram do sexo feminino e 25 (61\%) do sexo masculino. A média de idade desse grupo foi igual a 17,5 meses $(\mathrm{DP}=3,5)$. Das 9 crianças com apego inseguro, $3(33,3 \%)$ eram do sexo feminino e $6(66,7 \%)$ do sexo masculino. A média de idade deste grupo foi igual a 19 meses $(\mathrm{DP}=3,5)$.

Informações da estrutura familiar e da classe socioeconômica constam na Tabela 1 .

TABELA 1

Características sociodemográficas da amostra.

\begin{tabular}{|c|c|c|}
\hline \multirow[b]{2}{*}{ Variáveis sociodemográficas } & \multicolumn{2}{|c|}{ Padrão de apego } \\
\hline & $\begin{array}{l}\text { Seguro } \\
f(\%)\end{array}$ & $\begin{array}{c}\text { Inseguro } \\
f(\%)\end{array}$ \\
\hline \multicolumn{3}{|l|}{ Escolaridade materna } \\
\hline Fundamental completo & $8(19,5)$ & $2(22,2)$ \\
\hline Médio Completo & $15(36,5)$ & $5(55,6)$ \\
\hline Superior completo & $18(44)$ & $2(22,2)$ \\
\hline \multicolumn{3}{|l|}{ Escolaridade paterna } \\
\hline Fundamental completo & $6(15,4)$ & $3(33,3)$ \\
\hline Médio Completo & $18(46,1)$ & $4(44,5)$ \\
\hline Superior completo & $15(38,5)$ & $2(22,2)$ \\
\hline \multicolumn{3}{|l|}{ Ocupação da mãe } \\
\hline Trabalha & $26(63,5)$ & $5(55,5)$ \\
\hline Não trabalha & $15(36,5)$ & $4(44,5)$ \\
\hline \multicolumn{3}{|l|}{ Ocupação do pai } \\
\hline Trabalha & $39(97,5)$ & $8(88,9)$ \\
\hline Não trabalha & $1(2,5)$ & $1(11,1)$ \\
\hline \multicolumn{3}{|l|}{ Situação parental } \\
\hline Mãe solteira & $2(4,9)$ & 0 \\
\hline Separados & $2(4,9)$ & $2(22,2)$ \\
\hline Casados/união estável & $37(90,2)$ & $7(77,3)$ \\
\hline \multicolumn{3}{|l|}{ Número de irmãos } \\
\hline 0 & $22(55)$ & $4(44,4)$ \\
\hline 1 & $12(30)$ & $1(11,1)$ \\
\hline 2 & $5(12,5)$ & $3(33,3)$ \\
\hline$<2$ & $1(2,5)$ & $1(11,1)$ \\
\hline \multicolumn{3}{|l|}{ Classe socioeconômica } \\
\hline A & $8(19,5)$ & 0 \\
\hline $\mathrm{B}$ & $17(41,5)$ & $5(55,6)$ \\
\hline $\mathrm{C}$ & $16(44)$ & $4(44,4)$ \\
\hline \multicolumn{3}{|l|}{ Creche } \\
\hline Um período & $13(31,7)$ & $1(11,1)$ \\
\hline Integral & $6(14,6)$ & $3(33,3)$ \\
\hline Não frequenta & $22(53,7)$ & $5(55,6)$ \\
\hline \multicolumn{3}{|l|}{ Idade materna (anos) } \\
\hline Média (DP) & $32,2(6,1)$ & $33,5(8,2)$ \\
\hline \multicolumn{3}{|l|}{ Idade paterna (anos) } \\
\hline Média (DP) & $34,3(8,4)$ & $37,9(9,5)$ \\
\hline
\end{tabular}


A maior parte das mães das crianças com apego seguro tinham ensino superior completo (44\%), enquanto que no grupo de crianças com apego inseguro a maior parte das mães $(55,6 \%)$ tinham apenas ensino médio completo. Por outro lado, em ambos os grupos a escolaridade paterna predominante foi de ensino médio completo. Mais da metade das mães da amostra estavam trabalhando, $63,5 \%$ das mães de crianças com apego seguro e 55,5\% das mães de crianças com apego inseguro realizavam algum tipo de trabalho fora de casa. Da mesma forma, a grande maioria dos pais, em ambos os grupos, estavam empregados. Com relação a classe econômica, enquanto $19,5 \%$ das famílias das crianças com apego seguro eram da classe A, nenhuma família das crianças com apego inseguro eram desta classe econômica. Quanto à escolarização das crianças, mais da metade em ambos os grupos não frequentavam a creche em nenhum período. Contudo, apesar destas diferenças, não foi encontrada diferença significativa entre os grupos em nenhuma das variáveis socioeconômicas.

A Tabela 2 mostra a comparação entre os grupos quanto as características de nascimento.

Quando analisadas as características de nascimento da amostra e comparando suas médias entre os grupos de padrão de apego seguro e inseguro, diferença estatisticamente significativa foi encontrada somente para as variáveis Apgar no $1^{\mathrm{O}}$ e no $5^{\mathrm{O}}$ minuto $(p=0,039$ e $p=0,010$, respectivamente).

A fim de verificar se características do estilo materno influenciaram o padrão de apego nas dimensões segurança e insegurança foi verificada a diferença, entre os grupos, às respostas a cada pergunta do questionário de Estilo Materno. Os itens 11 ("Eu ofereço para a minha criança atividades regulares e programadas fora de casa, como praticar algum tipo de esporte") e 14 ("Eu tenho paciência quando minha criança se comporta mal") mostraram diferenças entre as duas amostras $(p=0,003$ e $p=0,011)$, sendo as menores pontuações observadas no grupo de crianças com apego inseguro.

A pontuação escalar do Questionário Socialemocional da BSID III dos dois grupos, crianças com padrão de apego inseguro e crianças com padrão de apego seguro, foi comparada, assim como as respostas para cada pergunta individualmente. $O$ único item do questionário que mostrou diferença de resposta entre os grupos foi o item $21 \quad(p=0,033)$, que consiste no enunciado "Usa palavras ou tenta usá-las quando as pessoas falam ou brincam com ele", Em uma escala de resposta que varia de 1 a 5, teve como média 2,5 de pontuação no grupo com padrão de apego inseguro e 3,71 de média de reposta no grupo de padrão de apego seguro.

Verificou-se, também, se havia diferença entre os grupos quanto ao nível de desenvolvimento cognitivo, da linguagem e da motricidade. Os resultados constam na Tabela 3.

Diferença significativa entre os grupos, crianças com padrão de apego seguro e crianças com padrão de apego inseguro, foi constada nas escalas cognição $(p=0,028)$ e linguagem total $(p=0,026)$.

TABELA 2

Comparação das médias das variáveis de nascimento em relação ao padrão de apego.

\begin{tabular}{|c|c|c|c|c|c|c|}
\hline Variável & Padrão de Apego & Média & Minimo & Máximo & Desvio padrão & Valor de $p$ \\
\hline \multirow[t]{2}{*}{ Idade gestacional } & Inseguro & 32,3 & 25,4 & 39,0 & 4,0 & $0,106^{(2)}$ \\
\hline & Seguro & 34,9 & 27,0 & 420 & 4,3 & \\
\hline \multirow[t]{2}{*}{ Internação (dias) } & Inseguro & 37,9 & 0 & 120 & 36,2 & $0,119^{(1)}$ \\
\hline & Seguro & 24,4 & 0 & 114 & 33,2 & \\
\hline \multirow[t]{2}{*}{ Apgar $1^{\circ}$ minuto } & Inseguro & 6,1 & 4 & 8 & 1,8 & $\mathbf{0 , 0 3 9} 9^{(1)}$ \\
\hline & Seguro & 7,3 & 1 & 9 & 2,1 & \\
\hline \multirow[t]{2}{*}{ Apgar 5 minuto } & Inseguro & 7,9 & 4 & 9 & 1,6 & $\mathbf{0 , 0 1 0}(1)$ \\
\hline & Seguro & 9,1 & 5 & 10 & 1,1 & \\
\hline \multirow[t]{2}{*}{ Peso ao nascimento } & Inseguro & 1741 & 890 & 3190 & 712 & $0,147^{(2)}$ \\
\hline & Seguro & 2259 & 915 & 4290 & 999 & \\
\hline \multirow[t]{2}{*}{ Perímetro cefálico } & Inseguro & 29,9 & 28,0 & 33,0 & 1,8 & $0,608^{(2)}$ \\
\hline & Seguro & 30,4 & 23,6 & 39,0 & 4,3 & \\
\hline
\end{tabular}

(1) Teste não-paramétrico de Mann-Whitney, $\mathrm{p}<0,05$.

(2) Teste $t$ de Student para amostras independentes, $\mathrm{p}<0,05$. 
TABELA 3

Comparação das médias obtidas nas Escalas Bayley em relação ao padrão de apego.

\begin{tabular}{|c|c|c|c|c|c|c|}
\hline Variável & Padrão de apego & Média & Mínimo & Máximo & Desvio padrão & Valor de $p^{(l)}$ \\
\hline \multirow[t]{2}{*}{ Cognição } & Inseguro & 8,2 & 5 & 11 & 1,9 & 0,028 \\
\hline & Seguro & 10,0 & 4 & 15 & 2,4 & \\
\hline \multirow[t]{2}{*}{ Linguagem receptiva } & Inseguro & 9,0 & 6 & 14 & 2,9 & 0,081 \\
\hline & Seguro & 10,7 & 4 & 15 & 2,4 & \\
\hline \multirow[t]{2}{*}{ Linguagem expressiva } & Inseguro & 8,4 & 6 & 12 & 2,1 & 0,061 \\
\hline & Seguro & 10,0 & 5 & 15 & 2,2 & \\
\hline \multirow[t]{2}{*}{ Linguagem total } & Inseguro & 17,4 & 13 & 25 & 4,5 & 0,026 \\
\hline & Seguro & 20,7 & 9 & 29 & 4,0 & \\
\hline \multirow[t]{2}{*}{ Motricidade fina } & Inseguro & 10,1 & 8 & 14 & 2,2 & 0,602 \\
\hline & Seguro & 10,5 & 7 & 15 & 2,3 & \\
\hline \multirow[t]{2}{*}{ Motricidade grossa } & Inseguro & 9,3 & 6 & 13 & 2,2 & 0,804 \\
\hline & Seguro & 9,5 & 1 & 17 & 3,0 & \\
\hline \multirow[t]{2}{*}{ Motricidade total } & Inseguro & 19,4 & 14 & 26 & 4,3 & 0,619 \\
\hline & Seguro & 20,0 & 10 & 30 & 4,2 & \\
\hline
\end{tabular}

(1) Teste não-paramétrico de Mann-Whitney, $\mathrm{p}<0,05$.

\section{Discussão}

Durante os primeiros anos de vida a criança desenvolve dois sistemas que a auxiliam na interação com o ambiente: o sistema de apego e o sistema de exploração. O primeiro consiste na busca de proximidade e proteção do cuidador em face do desconforto e do perigo, enquanto o segundo está relacionado à exploração do ambiente e seus objetos a fim de conhecê-los. Trata-se de dois sistemas antagônicos, enquanto um é acionado o outro é, ainda que parcialmente, inibido. Ao longo do desenvolvimento a condição mais favorável é que o equilíbrio entre eles esteja presente (Cassidy \& Shaver, 2008). Isso demonstra a importância de um padrão de apego seguro, em que a criança tem a mãe como base segura para que possa explorar o ambiente.

O padrão de apego predominante neste estudo foi o seguro, tipo B (82\%), semelhante ao que é encontrado na literatura. De acordo com Main (2000), este tipo de apego é preponderante na maioria das amostras, podendo haver uma pequena variação entre diferentes culturas.

A maior parte das mães das crianças com apego seguro tinham ensino superior completo (44\%), enquanto que no grupo de crianças com apego inseguro a maior parte das mães $(55,6 \%)$ tinham apenas ensino médio completo. Por outro lado, em ambos os grupos a escolaridade paterna predominante foi de ensino médio completo. Este é um fator relevante, uma vez que a escolaridade parental tem sido apontada como fator de influência para o desenvolvimento da criança, ainda durante o primeiro ano de vida (Piccolo, Sbicigo,
Grassi-Oliveira, \& Salles, 2016). A baixa escolaridade parental, principalmente a materna, constitui um fator de risco ao desenvolvimento infantil, enquanto que níveis mais altos de escolaridade são considerados fator de proteção ao desenvolvimento global e específico (Pereira, Valentini \& Saccani, 2016).

Quanto à ocupação profissional, 63,5\% das mães de crianças com apego seguro e $55,5 \%$ das mães de crianças com apego inseguro estavam trabalhando, assim como a grande maioria dos pais, em ambos os grupos. No que diz respeito à estrutura familiar, prevaleceu entre os pais das crianças dos dois grupos o casamento/união estável. Ainda, no grupo de crianças com apego seguro, 85\% eram filhos únicos ou tinham apenas um irmão, enquanto que no grupo de crianças com apego inseguro esta porcentagem foi mais baixa, de $55 \%$.

Simões, Farate, Soares e Duarte (2013) analisaram a relação entre apego e estrutura familiar em crianças em idade escolar. Segundo os autores, o tipo de família, a estrutura familiar e a situação parental não são preditores do padrão de apego. No entanto, alguns estudos demonstram diferenças na dinâmica familiar entre famílias com um e com mais filhos que poderiam interferir no padrão de apego. $\mathrm{O}$ investimento parental pode ser diferente de acordo com a ordem de nascimento da criança (Uggla \& Mace, 2016). Com o primeiro filho, as mães investem mais tempo por dia em interação do que mães quem têm outros filhos mais velhos (Price, 2008). Quando a família possui apenas um filho todo o investimento financeiro, de tempo e atenção, vai para ele. Se há dois filhos, o investimento 
aplicado a ambos tende a ser o mesmo, mas a idade da criança em que este investimento ocorre pode ser diferente (Hertwig, Davis \& Sulloway, 2002). Contudo, em uma pesquisa recente, foi averiguado que o tipo de família, a estrutura familiar e a situação parental não são preditores do padrão de apego daquelas crianças (Simões, Farate, Soares \& Duarte, 2013).

$\mathrm{Na}$ presente pesquisa, diferenças entre os grupos com relação às características sociodemográfica não foram encontradas. Do mesmo modo, as características de nascimento também foram comparadas. A análise mostrou diferença entre os grupos no Apgar no $1^{\mathrm{O}}$ $(p=0,039)$ e no $5^{\circ}$ minuto $(p=0,010)$, em que ambos os valores de Apgar se mostraram mais baixos nas crianças inseguramente apegadas.

Pesquisas demonstram que os valores baixos de Apgar no $1^{\mathrm{O}}$ e no $5^{\mathrm{O}}$ minuto podem estar associados ao padrão de apego desorganizado (Pennestri et al., 2015) e ao apego ambivalente (Ainsworth et al., 1978). No presente estudo, os padrões inseguros de apego foram agrupados em apenas uma categoria, o que impossibilitou a análise independente de cada padrão, o que auxiliaria a determinar se um dos tipos de insegurança pode, especificamente, estar relacionado ao valor de Apgar.

Ainda, buscou-se averiguar a diferença entre os grupos em relação ao estilo materno, uma vez que, para Bowlby (2002), a conduta materna desempenha um papel essencial na determinação do tipo de padrão de apego da criança, principalmente no que diz respeito à sensibilidade e responsividade. Foi aplicado, nas mães, um instrumento com questões pertinentes à conduta materna em aspectos didáticos, sociais e disciplinares da educação. Das 17 perguntas propostas, que dizem respeito à frequência de determinados comportamentos maternos, em apenas dois itens os grupos apresentaram diferença significativa

Um dos itens consiste no enunciado "Eu ofereço para a minha criança atividades regulares e programadas fora de casa, como praticar algum tipo de esporte". Ambos os grupos tiveram média baixa de frequência de comportamento nesta questão, evidenciando que, além da ida a creche, eram oferecidas, para as crianças da presente amostra, poucas atividades fora de casa que fossem programadas. $\mathrm{O}$ grupo de mães de crianças com padrão de apego inseguro demonstrava oferecer menos atividades programadas que promovam a socialização.

$\mathrm{O}$ item "Eu tenho paciência quando minha criança se comporta mal" mostrou média de frequência menor no grupo de mães de crianças com padrões inseguros de apego. A falta de paciência é característica de mães autoritárias, que impõe limites, estipulam regras de conduta e esperam obediência estrita dos seus filhos. Estas mães são pouco responsivas e lhes falta sensibilidade (Baumrind, 1971), atributos importantes da figura de apego para o desenvolvimento de um padrão de apego seguro.

O presente estudo buscou, como principal objetivo, averiguar se crianças com padrão de apego seguro e inseguro diferem quanto ao desempenho cognitivo, linguístico e motor. Diferença significativa foi encontrada nos domínios cognitivo $(p=0,028)$ e na linguagem $(p=0,026)$. Corroborando os achados aqui encontrados, foi averiguado, em uma meta-análise, que crianças com padrão seguro são mais competentes neste domínio do que as com padrões inseguros. As crianças seguras se mostram mais dispostas a interagir e se comunicar e, consequentemente, exercitam e aprendem mais a comunicação verbal; ao mesmo tempo, os pais de crianças inseguramente apegadas, como tendem a ser menos responsivos, os estimulam menos (Van Ijzendoor, Dijkstra, \& Bus, 1995).

De acordo com Main (1983), crianças com padrão de apego seguro usam mais palavras e morfemas durante a brincadeira. De fato, este dado foi averiguado na presente amostra. Um dos itens do Questionário Socioemocional da BSID III tinha como enunciado "Usa palavras ou tenta usá-las quando as pessoas falam ou brincam com ele". A média de frequência deste comportamento foi maior nas crianças com padrão de apego seguro quando comparadas às crianças com padrões inseguros de apego $(p=0,033)$.

Em relação ao desenvolvimento cognitivo, apesar de a associação entre cognição e padrão de apego não ter ser sido averiguada em todos os estudos, os âmbitos parecem estar associados, mesmo que em baixa intensidade. Especialmente, em amostras com maior número de crianças com o padrão inseguro ambivalente, foi encontrada menor performance neste domínio (Van Ijzendoor et al., 1995).

Em um estudo recente que avaliou a relação entre desenvolvimento da cognição e da linguagem e padrão de apego, crianças com apego seguro e inseguro diferiram significativamente em seu desempenho na avaliação dos dois domínios. Os pesquisadores também compararam o grupo de apego evitativo com o de apego seguro e este último com o grupo de apego ambivalente. Na primeira comparação a diferença no desempenho cognitivo e de linguagem de ambos os grupos foi pequeno, mas na segunda comparação a diferença de desempenho foi relevante, demonstrando que o apego inseguro ambivalente constitui um fator de risco maior para o desenvolvimento (Ding et al., 2014). Crianças com padrão de apego ambivalente ficam perturbadas em qualquer ambiente novo e estranho, sua capacidade de exploração é baixa, o que 
pode prejudicar o seu desenvolvimento cognitivo (Van Ijzendoor et al., 1995).

A segurança do apego, proporcionada por uma relação confiável e responsiva, possibilita para a criança explorar um ambiente novo sabendo que a figura de apego a socorrerá se necessário (Ainsworth \& Bowlby, 1991). A exploração do ambiente, que inclui a exploração de brinquedos e objetos, tem demonstrado exercer papel importante em diversos domínios do desenvolvimento. No que se refere à cognição, a exploração é um meio de gerar informação, sendo reconhecido como propulsor do desenvolvimento cognitivo. A exploração dos objetos, pela criança pequena, e seus esforços de explorar e agir sobre o mundo constituem as raízes das competências cognitivas que se irão se desenvolver em uma idade posterior (Oudgenoeg-Paz, Leseman, \& Volman, 2014).

Outras características comportamentais, que estão relacionadas ao desenvolvimento cognitivo, mais frequentes nas crianças com padrão seguro de apego em comparação às com padrões inseguros, são que elas brincam e interagem mais, e dispensam atenção por mais tempo aos brinquedos e aos objetos em lugares desconhecidos. Não obstante, durante atividades e brincadeiras as crianças seguramente apegadas são mais cooperativas com a mãe e com outras pessoas, característica que possibilita que elas aprendam com os adultos mais facilmente do que as crianças que não demonstram cooperação (Main, 1983).

Estes dados apontam para a compreensão de que o padrão de apego seguro proporciona uma melhor perspectiva para o desenvolvimento cognitivo durante a infância. Porém, outra hipótese indica que o desenvolvimento cognitivo subsidia a formação do apego seguro. Bowlby (2002) expõe processos essenciais para a seleção da figura de apego e o desenvolvimento da relação, que incluem a tendência para olhar, ouvir e se orientar para determinados estímulos; competência atencional em direção aos seus cuidadores; e a capacidade de perceber e aprender as características destes e os distinguir de outras pessoas. Para o autor, é necessário que a criança tenha adquirido a consciência da figura de apego para que seja possível estabelecer o vínculo, assim como o comportamento de orientação, a fim de buscar sua companhia. Para que a fase de apego possa ser estabelecida é necessário que a criança já tenha adquirido a noção de permanência de objeto e ter desenvolvido representações internas da figura, de si mesma e do ambiente, formando mapas cognitivos que a auxiliarão a organizar o comportamento de acordo com planos (Ainsworth et al., 1978).

Para os autores que defendem a influência da cognição na relação de apego, o nível de maturidade cognitiva no qual a criança se encontra exercerá influência no padrão de apego que ela irá estabelecer. Associado às experiências individuais e condições ambientais, o aspecto cognitivo contribuirá para permitir maior leque de possibilidades quanto ao seu desenvolvimento (Fingergut, 2011).

O presente estudo demonstrou que há diferença no desenvolvimento da cognição e da linguagem em crianças com padrão de apego seguro e em crianças com padrão de apego inseguro. Um fator importante neste estudo é a composição da amostra, formada tanto por crianças nascidas PT, como AT. Os resultados aqui encontrados enfatizam a importância que as relações e as experiências iniciais da criança têm no seu desenvolvimento e trazem implicações para a prática clínica, demonstrando a relevância do vínculo de apego e a importância da orientação da equipe de saúde para a estimulação do vínculo entre mãe e filho.

\section{Referências}

Ainsworth, M., D. S., Bleher, M. C., Waters, E., \& Wall, S. (1978). Patters of attachment. A psychological study of the Strange Situation. New York: Psychology Press.

Ainsworth, M. S., \& Bowlby, J. (1991). An ethological approach to personality development. American psychologist, 46(4), 333-341. https://doi.org/10.1037/0003-066X.46.4.333

Associação Brasileira de Empresas de Pesquisa (ABEP) (2014). Critério de Classificação Econômica Brasil 2015.

Baumrind D. (1971). Current patterns of parental authority. Dev Psychol, 4(1, Pt 2), 1-103. https://doi.org/10.1037/ h0030372

Bayley, N. (2006). Bayley Scales of Infant and Toddler Development-Third Edition: Administration Manual. San Antonio: Harcourt Assessment.

Bornstein, M. H., Tamis-LeMonda, C. S., Parcual, L., Haynes, O. M., Painter, K. M., Galperín, C. Z., \& Pêcheux, M. G. (1996). Ideas about parenting in Argentina, France and the United States. International Journal of Behavioral Development, 19 (2), 347-367. https://doi.org/10.1080/016502596385820

Bowlby, J.. (2002). Apego e perda: Apego: a natureza do vínculo (3a ed., Vol. 1). São Paulo: Martins Fontes.

Cassidy, J., \& Shaver, P. (Eds). (2008). Handbook of attachment: Theory, Research and clinical applications (2 $\underline{\underline{a}}$ ed.). New York: The Guilford Press. 
Ding, Y. H., Xu, X., Wang, Z. Y., Li, H. R., \& Wang, W. P. (2014). The relation of infant attachment to attachment and cognitive and behavioural outcomes in early childhood. Early human development, 90(9), 459-464. https://doi. org/10.1016/j.earlhumdev.2014.06.004

Fingergut, D. M. (2011). Apego e resiliência: construindo e re-significando vínculos. Monografia de pós-graduação, Instituto Superior de Ciências da Saúde (INCISA), Salvador, Brasil. Doi inexistente

Gander, M., \& Buchheim, A. (2015). Attachment classification, psychophysiology and frontal EEG asymmetry across the lifespan: a review. Frontiers in human neuroscience, 9, 79. https://doi.org/10.3389/fnhum.2015.00079

Hertwig, R., Davis, J. N., \& Sulloway, F. J. (2002). Parental investment: how an equity motive can produce inequality. Psychological bulletin, 128(5), 728. https://doi.org/10.1037/0033-2909.128.5.728

Jouen, F., \& Molina, M. (2005). Exploration of the newborn's manual activity: A window onto early cognitive processes. Infant Behavior and Development, 28(3), 227-239. https://doi.org/10.1016/j.infbeh.2005.05.001

Main, M. (1983). Exploration, play, and cognitive functioning related to infant-mother attachment. Infant Behavior and Development, 6(2-3), 167-174. https://doi.org/10.1016/S0163-6383(83)80024-1

Main, M. (2000). The organized categories of infant, child, and adult attachment: Flexible vs. inflexible attention under attachment-related stress. Journal of the American Psychoanalytic Association, 48(4), 1055-1096. https://doi.org/10. 1177/00030651000480041801

Oudgenoeg-Paz, O., Leseman, P. P., \& Volman, M. C. J. (2014). Can infant self-locomotion and spatial exploration predict spatial memory at school age? European Journal of Developmental Psychology, 11(1), 36-48. https://doi.or g/10.1080/17405629.2013.803470

Pallini, S., Baiocco, R., Baumgartner, E., Bellucci, M. T., \& Laghi, F. (2016). Attachment in Childcare Centers: Is it Related to Toddlers' Emotion Regulation and Attentive Behavior?. Child Indicators Research, 1-16. https://doi. org/10.1007/s12187-016-9371-5

Pennestri, M. H., Gaudreau, H., Bouvette-Turcot, A. A., Moss, E., Lecompte, V., Atkinson, L., Lydon, J., Steiner, M., \& Meaney, M. J. (2015). Attachment disorganization among children in neonatal intensive care unit: Preliminary results. Early human development, 91(10), 601-606. https://doi.org/10.1016/j.earlhumdev.2015.07.005

Pereira, K. R., Valentini, N. C., \& Saccani, R. (2016). Brazilian infant motor and cognitive development: Longitudinal influence of risk factors. Pediatrics International. https://doi.org/10.1111/ped.13021

Piccolo, L. R., Sbicigo, J. B., Grassi-Oliveira, R., \& Salles, J. F. (2016) Efeitos do nível socioeconômico no desempenho neuropsicomotor de crianças e adolescentes. Em Neuropsicologia do Desenvolvimento: infância e adolescência. (J. F. Salles, V. G. Haase \& L. F. Malloy-Diniz). Porto Alegre: Artmed.

Price, J. (2008). Parent-Child Quality Time Does Birth Order Matter?. Journal of Human Resources, 43(1), $240-265$. https://doi.org/10.3368/jhr.43.1.240

Sajaniemi, N., Mäkelä, J., Salokorpi, T., Von Wendt, L., Hämäläinen, T., \& Hakamies-Blomqvist, L. (2001). Cognitive performance and attachment patterns at four years of age in extremely low birth weight infants after early intervention. European Child \& Adolescent Psychiatry, 10(2), 122-129. https://doi.org/10.1007/s007870170035

Seidl de Moura, M. L., \& Ribas Jr., R. C. (2003). Algumas informações sobre o instrumento estilo materno e paterno. Relatório parcial do projeto: interação mãe-bebê e desenvolvimento infantil: um estudo longitudinal e transcultural. Material não-publicado, Universidade do Estado do Rio de Janeiro.

Simões, S. C. C., Farate, C., Soares, I., \& Duarte, J. (2013). Predição do apego de crianças em função do estilo educativo materno e do tipo de família. Psicologia: Reflexao \& Critica, 26(1), 168-177. https://doi.org/10.1590/ S0102-79722013000100018

Sullivan, R. M. (2012). The neurobiology of attachment to nurturing and abusive caregivers. The Hastings law journal, 63(6), 1553.

Sullivan, R., Perry, R., Sloan, A., Kleinhaus, K., \& Burtchen, N. (2011). Infant bonding and attachment to the caregiver: insights from basic and clinical science. Clinics in perinatology, 38(4), 643-655. https://doi.org/10.1016/ j.clp.2011.08.011

Uggla, C. \& Mace, R. (2016). Parental investment in child health in sub-Saharan Africa: a cross-national study of health-seeking behaviour. Open Science, 3(2), 150460. https://doi.org/10.1098/rsos.150460

Van Ijzendoorn, M. V., Dijkstra, J., \& Bus, A. (1995). Attachment, intelligence, and language: A meta-analysis. Social Development, 4, 115-128. https://doi.org/10.1111/j.1467-9507.1995.tb00055.x

Dados dos autores:

Bárbara Saur - Mestra, Universidade Federal do Paraná.

Isac Bruck - Mestre, Universidade Federal do Paraná.

Sérgio Antonio Antoniuk - Doutor, Universidade Federal do Paraná

Tatiana Izabele Jaworski de Sá Riechi - Pós-Doutor, Universidade Federal do Paraná.

Endereço para correspondência:

Bárbara Saur

Rua Monsenhor Manoel Vicente 605, apto 14 - Bairro Água Verde

80620-230 Curitiba, PR, Brasil

<barbara.saur@gmail.com>

Recebido em: 24.04.2017

Aceito em: 15.01.2018 